\title{
Варисторный эффект в сильногетерогенных системах полимер-ZnO
}

\author{
() М.А. Курбанов ${ }^{1}$, Ш.М. Ахадзаде ${ }^{1}$, И.С. Рамазанова ${ }^{1}$, З.А. Дадашов ${ }^{1}$, И.А. Фараджзаде ${ }^{2}$ \\ ${ }^{1}$ Институт фризики Национальной академии наук Азербайджана, \\ Az-1143 Баку, Азербайджан \\ ${ }^{2}$ Институт радиационных проблем Национальной академии наук Азербайджана, \\ Az-1143 Баку, Азербайджан \\ E-mail: mKurbanov@physics.ab.az
}

(Получена 16 ноября 2016 г. Принята к печати 28 ноября 2016 г.)

Исследованы композитные варисторы на основе полярных и неполярных полимеров (матрица) и неорганической фазы (диспергатор) ZnO. Показано, что вариацией физической структуры гетерогенной системы полимер- $\mathrm{ZnO}$ можно разработать композитные варисторы с высокой напряженностью электрического поля пробоя и коэффициентом нелинейности. В качестве полимерной матрицы выбраны неполярный полиэтилен и неполярный поливинилиденфторид.

DOI: 10.21883/FTP.2017.07.44660.8390

\section{1. Введение}

Одним из перспективных направлений применения композитных материалов является использование их в качестве варисторов, т.е. в качестве нелинейного элемента, сопротивление которого зависит от приложенного напряжения [1-5]. Поиск варисторного эффекта в композитах предопределил существование потенциального барьера на границе полупроводников, сегнетопьезоэлектриков и полимеров, параметры которых зависят от напряженности электрического поля. Простота технологии изготовления композитных варисторов состоит в том, что неорганические полупроводниковые или сегнетопьезокерамические варисторы в основном изготавливаются по керамической и полимерной технологиям. Механические и электрические прочностные характеристики активных диэлектриков являются одним из важнейших эксплуатационных показателей в любой области их применения. Так, например, прохождение ударной волны по варисторам сопровождается возникновением в них электрического поля, способствующего ускоренному разрушению указанного элемента.

В настоящее время существуют в основном три направления в области создания варисторных элементов на основе активных твердых диэлектриков и полупроводников. Одно из них связано с созданием все новых и новых полупроводниковых варисторных материалов [1,2]. Второе базируется на синтезе новых полимерных диэлектриков, проявляющих варисторные свойства [3]. Третье направление связано с созданием различных композитов на основе полимеров (матрица) и неорганических полупроводников и сегнетопьезоэлектриков (диспергатор) [1]. Установление взаимосвязи между характеристиками композитных варисторов и со свойствами полимерной фазы и полупроводниковых наполнителей (диспергаторы), безусловно, является ключевым вопросом на пути решения этой весьма важной проблемы, заключающейся в создании более эффективных композитных варисторных элементов различных назначений.
Цель работы - разработка технологии создания композитных варисторных элементов с регулируемыми напряжением срабатывания и коэффициентом нелинейности. Известно, что определение влияния свойств полимерных матриц (органическая фаза) и $\mathrm{ZnO}, \mathrm{SiC}$ (неорганическая фаза) на напряжение срабатывания и коэффициент нелинейности композитного варистора является ключевым вопросом на пути создания их технологии. Свойства $\mathrm{ZnO}$ варьированы путем введения примесей небольших концентраций (3\%). Проведенные исследования показывают, что наиболее подходящим диспергатором для создания композитных варисторных элементов являются $\mathrm{ZnO}, \mathrm{SiO}_{2}, \mathrm{SiC}$ [6-8].

\section{2. Методика эксперимента}

В работе рассмотрены технологии плазменного модифицирования композитного варистора для целенаправленной вариации их напряжения срабатывания и коэффициента нелинейности (рис. 1). Способ получения материала предлагаемого состава для изготовления пленочных композитных варисторов состоит в следующем: изготовление пресс-порошка варисторной керамики; выбор порошка полимеров (полиэтилен ПЭ, поливинилиденфторид ПВДФ); смешивание порошков органической и неорганической фаз; методом горячего прессования получаем варисторный элемент. Размер частиц $\mathrm{ZnO}$ выбран от 60 до 320 мкм.

Затем полученную смесь помещают в пресс-форму и подвергают горячему прессованию следующим образом.

В начале смешанную порошковую смесь под давлением $P=1$ МПа подогревают до температуры плавления $\left(T=160^{\circ} \mathrm{C}\right)$ в течение 20 мин. Давление в прессе увеличивают до $P=15$ МПа. В этом положении выдерживают под давлением в течение 5 мин. Полученный пленочный композит охлаждают путем закалки в воде. После этого с помощью серебряной пасты на поверхность полученных образцов наносят измерительные электроды диаметром 10 мм. Коэффициент нелинейности определен по 


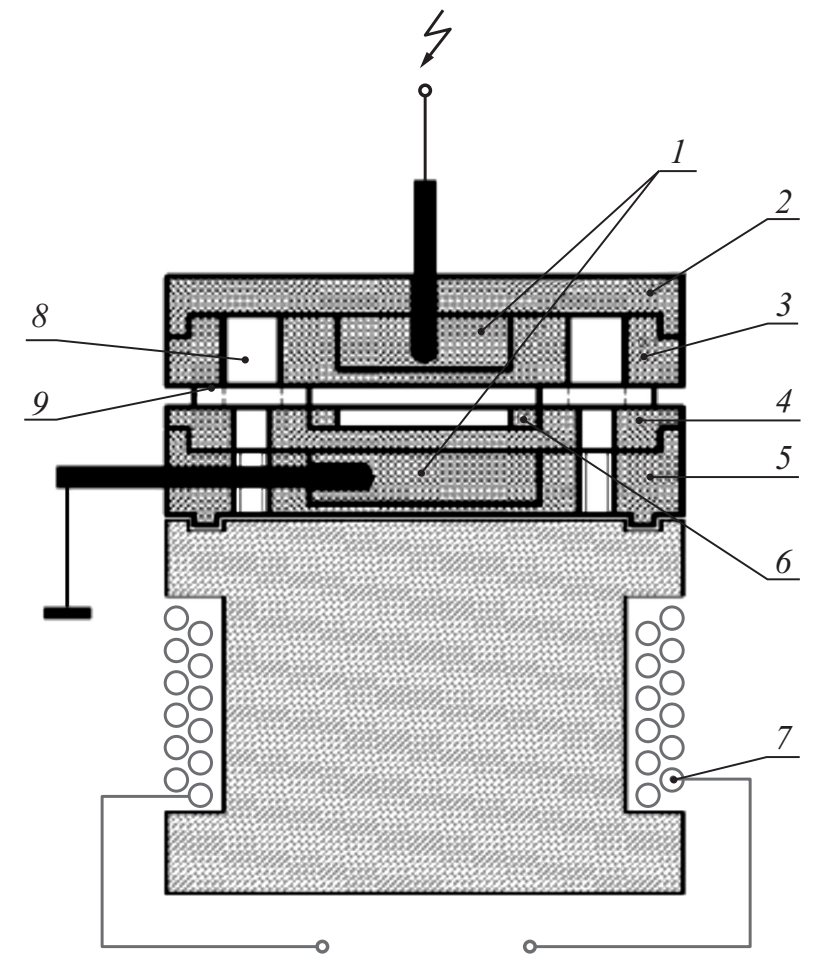

Pис. 1. Ячейка, предназначенная для химической модификации полимеров в условиях действия плазмы электрического разряда в газе, ограниченном композитными диэлектриками: 1 - электроды, 2 - диэлектрическая шайба, 3 - диэлектрический анод, 4 - диэлектрическая кювета (диэлектрический катод), 5 - изолятор, $6-$ шайба упорная, $7-$ нагревательный элемент, 8 - направляющий, 9 - диэлектрический ограничитель расстояния.

вольт-амперной характеристике варисторного элемента. Напряжение срабатывания варистора также определено по вольт-амперной характеристике.

В условиях наших экспериментов коэффициент нелинейности варистора изменяется в переделах от 3 до 8 . Эксперименты проведены при постоянно приложенном напряжении. Напряжение срабатывания композитных варисторов регулировалось в пределах от 30 до $600 \mathrm{~B}$. Электрическая прочность определялась по известной методике, приведенной в $[9,10]$. При определении механизма электрического разрушения композитных варисторов использован метод термоактивационной спектроскопии [7].

\section{3. Экспериментальные результаты и их обсуждение}

Известно, что напряжение срабатывания и коэффициент нелинейности являются определяющими параметрами композитных варисторных материалов. Поэтому определение влияния внешних факторов (электрического разряда, электрического и механического напряжений) на напряжение срабатывания и коэффициент нели- нейности композитов позволяют разработать варисторы различных назначений, в том числе маломощных и низковольтных.

На рис. 2 приведена вольт-амперная характеристика варисторов. При этом толщина варисторного элемента выбрана 320 мкм, а диаметр частиц $\mathrm{ZnO}$ варьирован от 63 до 320 мкм. В качестве действующего напряжения выбрано синусоидальное напряжение частотой 50 Гц. Полученные результаты показывают, что диаметр частиц $\mathrm{ZnO}$ существенно влияет на напряжение срабатывания композитного варистора. С увеличением диаметра частиц неорганической фазы напряжение срабатывания существенно уменьшается, а коэффициент нелинейности практически остается неизменным. Полученные результаты в первом приближении можно объяснить следующим образом.

- с увеличением диаметра частиц $\mathrm{ZnO}$ уменьшается эффективная толщина полимерной фазы между частицами $\mathrm{ZnO}$, между электродом и поверхностью частиц (рис. 3);

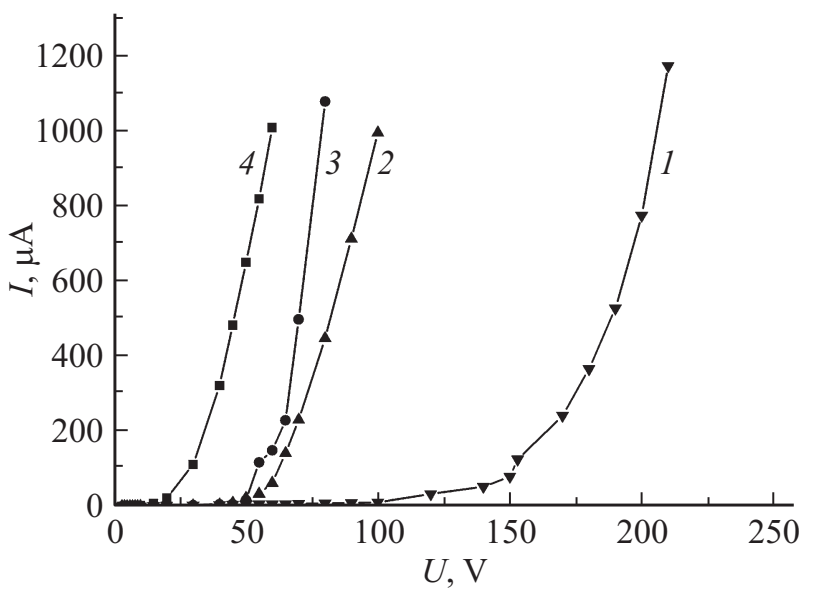

Рис. 2. Вольт-амперная характеристика варисторов $\mathrm{ZnO}-$ полимер с различными диаметрами частиц $\mathrm{ZnO}$. Объемное содержание $\mathrm{ZnO}$ выбрано 70\%; диаметр диспергатора $d$, мкм: $1-63,2-100,3-200,4-315$ мкм.

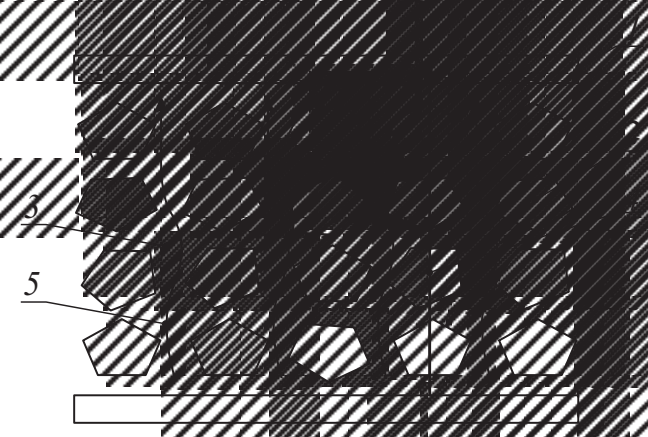

Рис. 3. Возможные пути переноса зарядов через композит полимер-ZnO: 1 - электрод, 2 - кристаллит, 3 - межкристаллитная граница, 4 - проводимость по кристаллитам разделенной полимерной прослойкой, 5 -проводимость по полимерной матрице. 


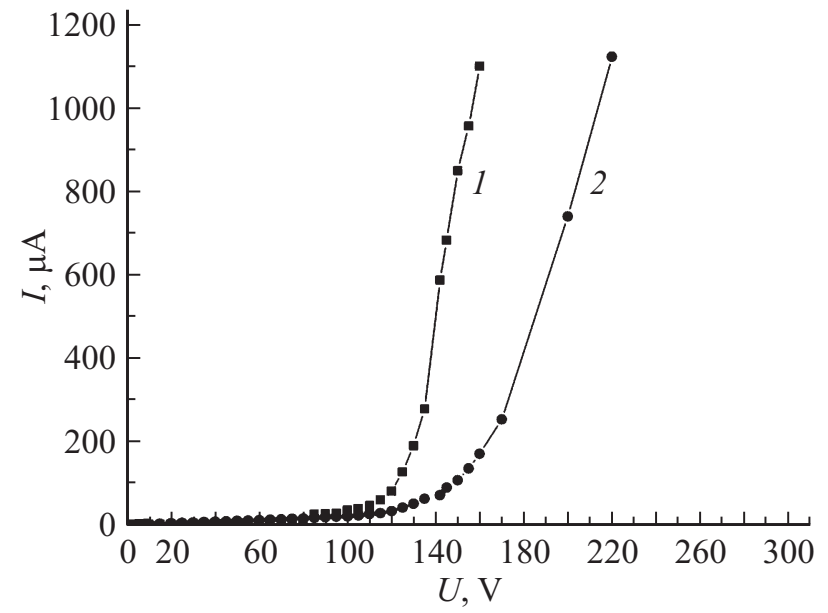

Рис. 4. Вольт-амперная характеристика композитного варистора на основе $\mathrm{ZnO}-П Э$ с различными примесями $(50 \% \mathrm{ZnO}+50 \%$ ПЭ): 1 - композитный варистор на основе ПЭ и $\mathrm{ZnO}$, легированный $\mathrm{Al}_{2} \mathrm{O}_{3} ; 2$ - композитный варистор на основе ПЭ и $\mathrm{ZnO}$, легированный $\mathrm{ZrO}_{2}$.

- более интересными являются линии тока, проходящие по полимерным прослойкам между частицами;

- переход линии тока по вышеуказанной картине зависит от сопротивления полимерной прослойки между частицами и самой частицы $\mathrm{ZnO}$.

Немаловажное значение имеет учет третьей фазы, связанной с формированием переходного слоя, структура которой формируется под действием поверхности частиц $\mathrm{ZnO}$.

На первый взгляд полученные результаты показывают, что в условиях наших экспериментов наблюдается аномальный эффект, так как с уменьшением размера частиц (при постоянном объемном содержании) напряжение срабатывания должно было бы уменьшаться. Однако полученные результаты показывают, что напряжение срабатывания варистора увеличивается, т.е. роль интегральной контактной поверхности в условиях наших экспериментов (при вариации размера частиц $\mathrm{ZnO}$ от 63-320 мкм) не реализуется.

Как было уже отмечено, что на характеристики изучаемых композитных варисторов существенно влияют полярность полимерной матрицы и свойства неорганической фазы. На рис. 4 показана вольт-амперная характеристика композитов на основе полиэтилена и $\mathrm{ZnO}$, легированной $\mathrm{Al}_{2} \mathrm{O}_{3}$ и $\mathrm{ZrO}_{2}$. Полученные результаты показывают, что легирование неорганической фазы заметно влияет на напряжение срабатывания композитного варистора, а именно в случае $\mathrm{ZnO}+\mathrm{Al}_{2} \mathrm{O}_{3}$ напряжение срабатывания варистора меньше, чем аналогичного параметра, полученного для $\mathrm{ZnO}+\mathrm{ZrO}_{2}$. Более интересными являются результаты исследования о влиянии полярности полимерной матрицы на варисторные свойства композитов на основе поливинилиденфторида $(\Phi 2 \mathrm{M})$ (рис. 5, $a$ и $b$ ). Из сопоставления результатов этих исследований отчетливо видно, что коэффициент нелинейности композитов на основе полярного полимера $\mathrm{ZnO}-\Phi 2 \mathrm{M}$ заметно больше, чем у композитов $\mathrm{ZnO}-\Pi Э$.

Из вольт-амперной характеристики определено напряжение срабатывания вышеуказанных композитов (рис. 6, $a$ и $b$ ). Видно, что напряжение срабатывания композитов $\mathrm{ZnO}-\Phi 2 \mathrm{M}$ заметно меньше, чем у композитов $\mathrm{ZnO}-$ ПЭ. Механизм вышеуказанных эффектов представляет собой интерес и в первом приближении можно объяснить межфазными взаимодействиями на границе раздела компонентов композитов. Ранее нами было показано [11], что предварительное модифицирование композитов в условиях действия плазмы электрического разряда позволяет регулировать величину напряжения срабатывания композитов в широком интервале напряжений (рис. 7). Считаем, что такое изменение величины напряжения срабатывания композитов непосредственно связано с физико-химическими изменениями структу-
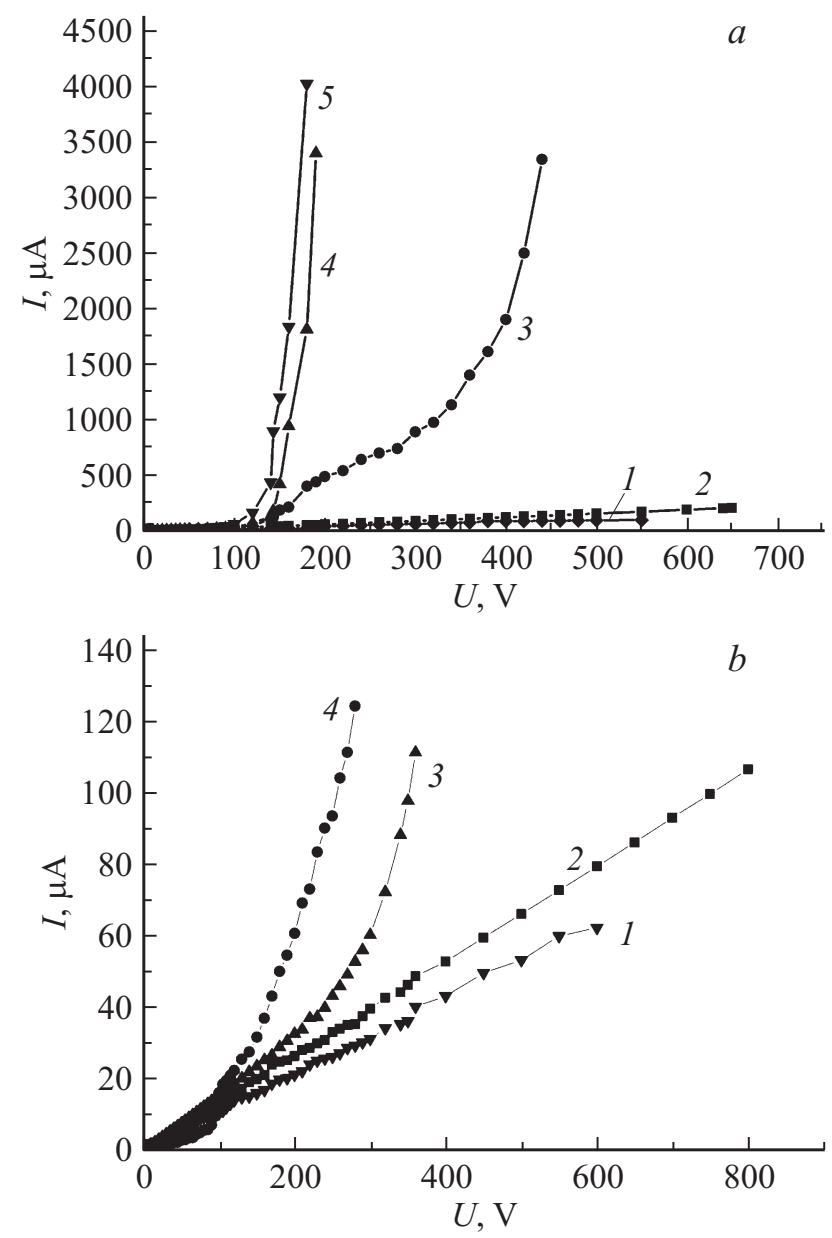

Рис. 5. $a-$ вольт-амперная характеристика композитного варистора на основе $\mathrm{ZnO}-\Phi 2 \mathrm{M}$ : $1-C=0 \%, \Phi 2 \mathrm{M}=100 \%$; $2-C=10 \%, \Phi 2 \mathrm{M}=90 \% ; 3-C=30 \%, \Phi 2 \mathrm{M}=70 \%$; $4-C=50 \%, \quad \Phi 2 \mathrm{M}=50 \% ; \quad 5-C=60 \%, \quad \Phi 2 \mathrm{M}=40 \%$. $b$ - вольт-амперная характеристика композитного варистора на основе $\mathrm{ZnO}-\Pi$ Э: $1-100 \% \Pi Э, 2-10 \% \mathrm{ZnO}+90 \% \Pi Э$, $3-30 \% \mathrm{ZnO}+70 \% \Pi \ni, 4-60 \% \mathrm{ZnO}+40 \% \Pi \ni$. 

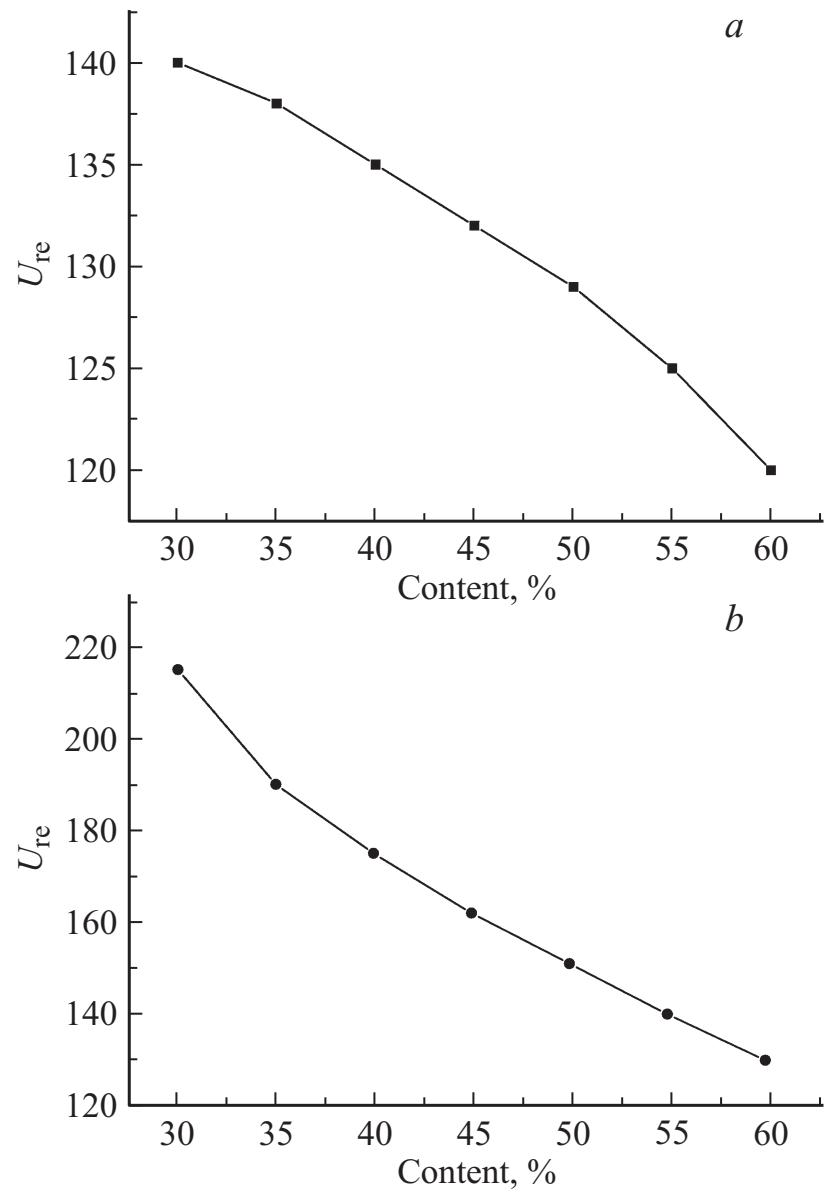

Рис. 6. $a-$ зависимость величины напряжения срабатывания варисторного композита $\mathrm{ZnO}-\Phi 2 \mathrm{M}$ от объемного содержания $\mathrm{ZnO} . b$ - зависимость величины напряжения срабатывания варисторного композита $\mathrm{ZnO}-$ ПЭ от объемного содержания $\mathrm{ZnO}$.

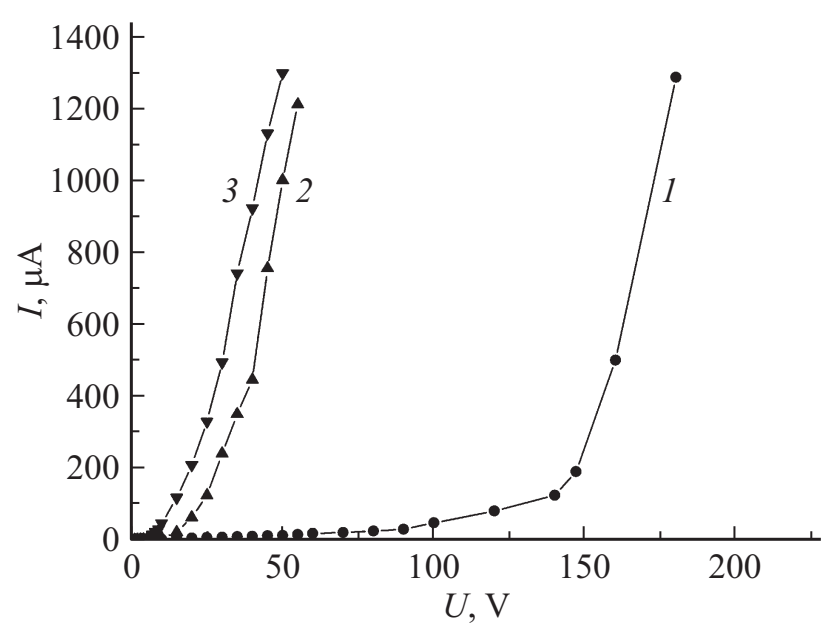

Рис. 7. Вольт-амперная характеристика варисторов, модифицированных в условиях действия плазмы электрического разряда: 1 - немодифицированный образец; 2 - образец, модифицированный в условиях действия плазмы электрического разряда в течение 3 мин; 3 - образец, модифицированный в условиях действия плазмы электрического разряда в течение 10 мин.
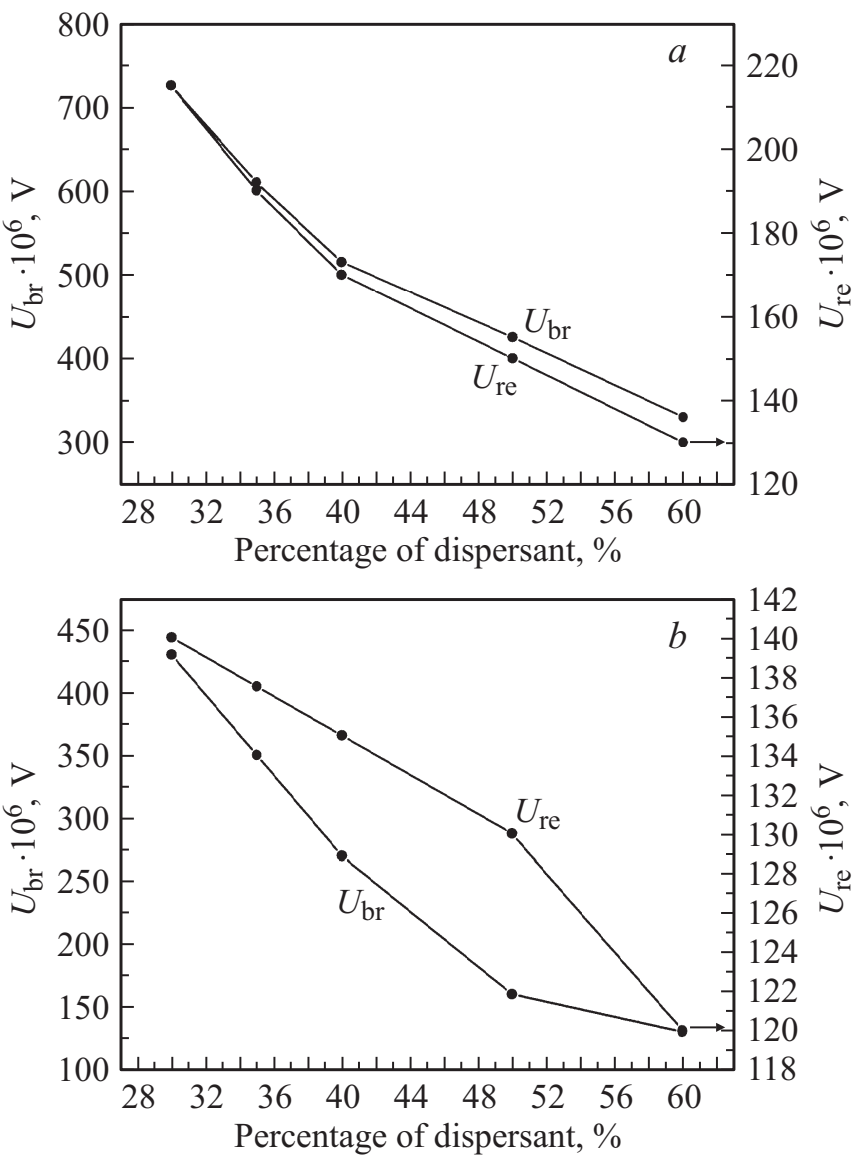

Рис. 8. $a$ - зависимость напряжений срабатывания и пробоя композитов $\mathrm{ZnO}-$ ПЭ от объемного содержания $\mathrm{ZnO} . b-$ зависимость напряжений срабатывания и пробоя композитов $\mathrm{ZnO}-\Phi 2 \mathrm{M}$ от объемного содержания $\mathrm{ZnO}$.

ры полимерной матрицы в условиях действия плазмы электрического разряда [7]. Полагаем, что любое изменение структуры полимерной фазы сопровождается возникновением локальных уровней в квазизапрещенной зоне и сдвигом уровня Ферми в сторону зоны проводимости. Уменьшается величина потенциального барьера на границе фаз. Поэтому срабатывание таких варисторов вызывает прохождение относительно большого по структуре $\mathrm{ZnO}$-полимер. Это в свою очередь приводит к увеличению коэффициента нелинейности композитного варистора в целом.

Одним из важнейших параметров варисторного элемента с точки зрения практического применения является его напряжение электрического пробоя $\left(U_{b r}\right)$. Эта величина практически определяет значение высокого предела напряжения срабатывания композитного варистора.

На рис. 8, $a$ и $b$ представлена зависимость величины напряжения электрического пробоя $\left(U_{b r}\right)$ и напряжения срабатывания $\left(U_{r e}\right)$ от объемного содержания неорганической фазы (диспергатор). Видно, что при всех значениях объемного содержания диспергатора величина $U_{b r}$ 
больше, чем $U_{r e}$. Аналогичные результаты получены и для варисторов на основе $\mathrm{ZnO}-\Phi 2 \mathrm{M}$. Для объяснения некоторых результатов по формированию варисторного эффекта в сильно гетерогенных материалах $\mathrm{ZnO-полимер} \mathrm{рассмотрим} \mathrm{роли} \mathrm{заряженных} \mathrm{частиц} \mathrm{и}$ релаксационных процессов в формировании электрического пробоя исследуемых варисторов. Отметим, что подобные исследования были проведены для полимеров в широком пределе температур в работе [7].

Известно, что начальной стадией электронно-ионных процессов в композитах в условиях действия сильного электрического поля является инжекция электронов в композит, стабилизация инжектированных электронов на различных ловушках полимерной фазы, перенос зарядов до границы раздела фаз и формирование потенциального барьера на границе $\mathrm{ZnO}$-полимер. Именно наличие потенциального барьера на границе раздела фаз определяет механизм формирования варисторного эффекта в указанных системах. Поэтому, по нашему мнению, исследования влияния релаксационных явлений инжектированных заряженных частиц на температурную зависимость электрического времени жизни композитных материалов представляет интерес с точки зрения создания маломощных варисторов различных назначений.

В работе [7] показано, что релаксационные явления в композитах являются главным фактором опустошения ловушек и, следовательно, возникновения свободных электронов, определяющих начало электрического пробоя гетерогенной системы $\mathrm{ZnO}$-полимер. Если учесть, что развитие релаксационных явлений тесно связано с температурой, то исследование температурновременной зависимости времени жизни варисторного материала позволит выявить роль инжектированных заряженных частиц и релаксационных процессов композита. На рис. 9, $a$ приведена зависимость электрического времени жизни от температуры. Наблюдаются максимумы при 175 и $250 \mathrm{~K}$. Такое изменение $\log \tau_{E}$ от температуры можно объяснить следующим образом:

- сопоставлением температурной зависимости времени жизни с термостимулированным деполяризационным током (ТСД) полимера (рис. 9, $b$ );

- определением источников образования свободных эффективных электронов, которые являются началом процесса электрического разрушения.

Согласно теории Артбауэра [12-14], наличие в полимерах газовых включений размером больше $50 \AA$ приводит к возникновению частичных разрядов, которые в конечном итоге сопровождаются разрушением (пробой) полимеров в сильном электрическом поле. Учитывая это, полагаем, что в гетерогенной системе полимер- $\mathrm{ZnO}$ на границе раздела фаз с большой вероятностью возникают газовые включения различных размеров. Именно эти очаги в сильном электрическом поле являются основной причиной электрического разрушения варисторных композитов полимер- $\mathrm{ZnO}$. Подтверждением этого эффекта является совпадение максимумов ТСД и зависимости $\log \tau_{E}=f(T)$ (рис. 9, $b$ ).
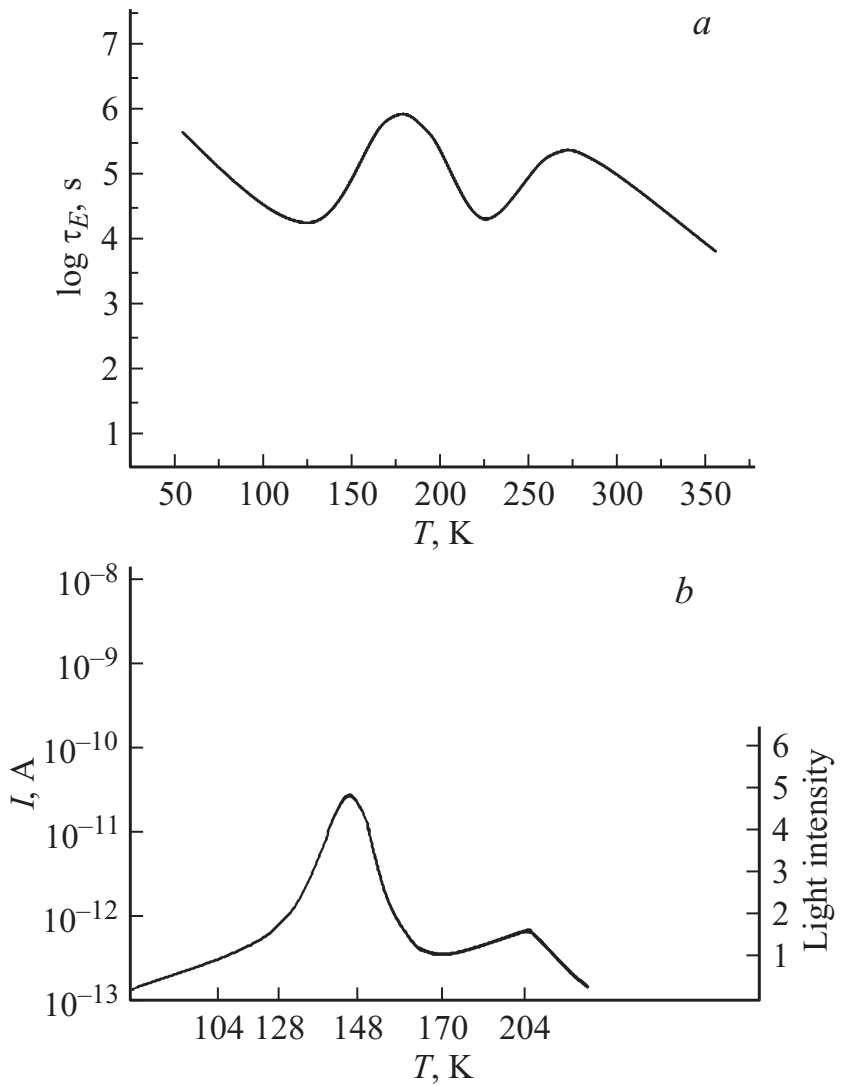

Рис. 9. $a-$ зависимость логарифма времени жизни полиэтилена от температуры. $b-$ спектр термостимулированного деполяризационного тока композита полимер- $\mathrm{ZnO}$.

Поэтому регулирование микроскопической физической структуры системы ПЭ- $\mathrm{ZnO}$ позволит создать композитные варисторы с высокой напряженностью электрического поля пробоя по сравнению с напряжением его срабатывания. Предложен возможный механизм регулирования напряжения срабатывания варисторов путем их плазменной модификации. Считаем, что плазменная модификация полимерной фазы варисторного элемента сопровождается возникновением локальных уровней в его квазизапрещенной зоне. Это, в свою очередь, сопровождается перемещением уровня Ферми к дну зоны проводимости. Этот процесс завершается электростатическим взаимодействием ионизованных уровней. Такое возможно при заметном увеличении концентрации ловушек, возникающих в результате плазменной модификации композита. Допускаем, что до плазменной модификации уровень Ферми практически располагается в середине запрещенной зоны полимера и определяет величину потенциального барьера на границе раздела фаз. Именно этот параметр, т. е. $E_{\mathrm{F}}^{\mathrm{ZnO}}-E_{\mathrm{F}}^{\mathrm{pol}}$, определяет величину напряжения срабатывания варистора. Любая модификация изучаемых композитов сопровождается изменением энергетической структуры запрещенной зоны полимерной матрицы или неорганической фазы $(\mathrm{ZnO})$. Модификация структуры полимерной матрицы 
осуществлена действием плазмы электрического разряда (рис. 1). Модификация неорганической фазы осуществлена путем введения примесей в $\mathrm{ZnO}\left(\mathrm{Al}_{2} \mathrm{O}_{3}, \mathrm{ZrO}_{2}\right)$.

\section{4. Заключение}

Полученные многочисленные экспериментальные результаты показывают, что более эффективной модификацией композитов является модификация их полимерной фазы [11] в условиях действия плазмы электрического разряда.

\section{Список литературы}

[1] А.Ю. Ляшков, А.С. Тонкошкур. ЖТФ, 81 (3), 112 (2011).

[2] М.К. Керимов, М.А. Курбанов, И.С. Султанахмедова, И.А. Фараджзаде, Ф.Н. Татардар, Х.С. Алиев. ФТП, 44 (7), 934 (2010).

[3] С.В. Горелов, Е.В. Иванова. Ползуновский вестн., 4, 238 (2005).

[4] А.А. Пикулев, В.М. Цветков. ЖТФ, 77 (9), 22 (2007).

[5] Л.Н. Тялина, А.М. Минаев, В.А. Пручкин. Новые композиционные материалы. Учеб. пособие (Тамбов, Изд-во ТГТУ, 2011).

[6] A.M. Hashimov, Sh.M. Hasanli, R.N. Mehtizadeh, Sh.M. Azizova, Kh.B. Bayramov. Phys. Status Solidi C, 8, 2871 (2006).

[7] М.А. Курбанов. Автореф. докт. дис. (Баку, 1985).

[8] А.М. Гашимов, Ш.М. Гасанли, Р.Н. Мехтизаде, Ш.М. Азизова, Х.Б. Байрамов. ФТП, 77 (8), 127 (2007).

[9] В.Г. Шевченко. Основы физики полимерных композиционных материалов. Учебн. пособие для студентов по специальности „Композиционные наноматериалы“(М., 2010).

[10] Э.Р. Блайт, Д. Блур. Электрические свойства полимеров. Пер. с англ. (М., Физматлит, 2008).

[11] L. Paral, M.A. Kurbanov, A.A. Bayramov, F.N. Tatardar, I.S. Ramazanova, G.X. Huseynova. J. Electron. Mater., 44 (11), 4322 (2015).

[12] J. Artbauer, J. Griac. Electrotech. Casopis, 16, 560 (1965).

[13] J. Artbauer. J. Phys. D: Appl. Phys., 29 (2), 446 (1996).

[14] J. Artbauer, J. Griac. Conf. of Dielectric and Insulating Materials, IEE (1964) p. 3.

Редактор Г.А. Оганесян

\section{Varistor effect in highly heterogeneous systems polymer-ZnO}

\section{M.A. Kurbanov ${ }^{1}$, Sh.M. Ahadzade ${ }^{1}$, I.S. Ramazanova ${ }^{1}$,} Z.A. Dadashov' ${ }^{1}$ I.A. Faradzhzade ${ }^{2}$

${ }^{1}$ Institute of Physics, National Academy of Sciences of Azerbaijan, Az-1143 Baku, Azerbaijan,

${ }^{2}$ Institute of Radiation Problems,

National Academy of Sciences of Azerbaijan, Az-1143 Baku, Azerbaijan

Abstract Composite varistors is studied based on polar and non-polar polymers and inorganic phace $\mathrm{ZnO}$. It is shown that the variation of the physical structure of $\mathrm{ZnO}$ heterogeneous polymer systems can be developed composite varistors with high electric breakdown field and nonlinearity coefficient. The nonpolar polyethylene (PE), polyvinylidene fluoride and a non-polar (F2M) are chosen as the polymer matrix. 